\title{
NIH panel may increase gene-trial scrutiny...
}

Paul Smaglik, Washington

The US National Institutes of Health (NIH) was last week urged to give its Recombinant DNA Advisory Committee (RAC) a greater role in the regulation of clinical trials for gene therapy. The call came from a working group set up to advise the NIH in the face of increasing concern over the conduct of such trials.

The advice runs counter to the policy of the former NIH administration, which had sought to diminish the RAC's involvement. It is also contrary to the wishes of clinical investigators, who are concerned about increasing amounts of red tape. But with legislators pushing for tighter control on clinical trials, such a move could reduce the pressure for congressionally mandated regulation.

Under the new proposals, enrolment in a clinical trial would not begin until the RAC had accepted the trial's protocols. If the committee found that a protocol was novel because, for example, it used a new kind of vector to deliver a gene, or sought to treat a new group of patients - the trial's investigator would have to present it formally to the RAC, which meets four times a year. Only after the committee was satisfied with the protocol would enrolment begin.

Christine Cassel of Mount Sinai Medical Center, and co-chair of the working group, told the NIH director's advisory committee meeting last week that only about 10 per cent of protocols would be subjected to this higher level of scrutiny. Before the new guidelines can come into effect, they need to be endorsed by acting NIH director Ruth Kirschstein, who has asked her advisory committee to comment on the proposals.

Claudia Mickelson, biosafety officer at

\section{... as Europe's 'excessive secrecy' is deplored}

\section{Declan Butler, Paris}

The recent difficulties faced by gene-therapy trials in the United States seem to have had little impact on attitudes to the regulation of such trials on the other side of the Atlantic.

This was the prevailing sentiment at a meeting of European scientists, regulators and industrialists involved in gene therapy, held in Paris last weekend. Indeed, several delegates deplored what they described as the excessive secrecy of European approval procedures for gene therapy.

The meeting was organized by Euregenethy, a grassroots network of scientists and physicians keen to promote gene therapy and the harmonization of regulatory laws across Europe.

The current plethora of national committees and rules is widely seen as a hindrance to clinical development, providing less clarity and concentration of expertise than would a single panEuropean procedure, and making it more difficult to organize the large trials needed to assess safety.

Speaker after speaker told the meeting that Europe's handling of gene therapy is anything but harmonized. Although new drugs are approved by the London-based European Medicines Evaluation
Agency, national governments must approve clinical trials. Only the United Kingdom, France, the Netherlands and Italy have dedicated systems for gene therapy in place.

In all countries, approvals depend on several different committees. Mark Richardson, head of regulatory affairs at Orio clinical services in Slough, UK, said that in such multi-stage reviews, the division of responsibilities between scientific, ethical and regulatory bodies is often unclear. As a result, approvals face long delays, and criteria for approval are unclear and differ from country to country.

The main organizer of the meeting, Odile Cohen-Haguenauer of the St Louis Hospital in Paris, is working on gene therapy for Fanconi anaemia, a rare childhood disorder. Despite progress in the laboratory, a multinational clinical trial will be "extremely difficult" to set up in Europe, she says.

Ted Friedmann, director of the programme in human gene therapy at the University of California, San Diego, and a member of the US Recombinant DNA Advisory Committee, said the meeting had taught him the "political realities" of the complexity of European regulation. Whatever the recent failings of the
US system, he said, it was at least "linear", and gave "much less opportunity for confusion".

Friedmann also said that if there was a lesson for Europe from the US controversy, it was of the need for building "openness" into regulatory structures: "over the last year we have learnt that open review is better than closed" (see Nature 405, 606-607; 2000). A marriage had to be found between legitimate industrial confidentiality "and the need for the public to know what happens".

Following the death of Jesse Gelsinger during a clinical trial run by the University of Pennsylvania's Institute for Human Gene Therapy in which high doses of adenoviral vector particles were given, Euregenethy has been carrying out a survey on the use of such vectors in Europe. It has found that many of the 30 ongoing or finished clinical trials have used them, some in similarly high doses.

Trials of the systemic application of adenoviral vectors have been put on hold by scientists themselves following Gelsinger's death, according to Euregenethy, while various European countries have begun to assess the safety of trials that have used adenoviral vectors. http://193.48.40.240//www/ euregenethy/euregenethy.html

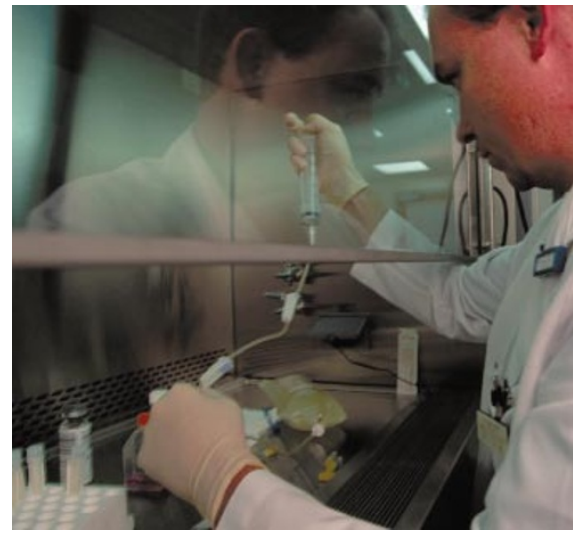

Bench-top bothers: there are fears that tighter RAC review could slow down clinical trials.

the Massachusetts Institute of Technology, RAC chair and a member of the working group that drafted the recommendations, denies that the RAC review would slow down the clinical-trial process. The proposals call for simultaneous review by the investigator's institutional review board, institutional biosafety committee and the RAC. Until now, such processes have been conducted sequentially.

In the past, novel protocols were sometimes reviewed by the RAC at the same time that investigators were enrolling patients, or even proceeding with the trials. "That's an untenable situation," says LeRoy Walters, former RAC chair and director of the Kennedy Institute of Ethics at Georgetown University in Washington DC, who has long been calling for the body to have more regulatory authority. "That just promotes disrespect."

Walters also notes that the new guidelines emphasize that the RAC is an advisory body to both the NIH and the Food and Drug Administration (FDA). These two bodies have sometimes had difficulty communicating with each other - especially over adverse events in clinical trials. This is another area the working group hopes to address, by harmonizing reporting to both agencies.

Even if the FDA recognizes the RAC as an advisory body, Walters says he has a "nagging concern" that gene-therapy trials funded and carried out by pharmaceutical companies could never have their adverse events made public. The RAC aims to disseminate such information in order to detect patterns and prevent the use of dangerous vectors, but the pharmaceutical industry is keen to keep adverse events confidential.

"We don't know that there aren't human gene-transfer protocols that have been submitted to the FDA that are totally invisible to the public review process," says Walters. 